\title{
Extreme Respiratory Sinus Arrhythmia Enables Overwintering Black Bear Survival-Physiological Insights and Applications to Human Medicine
}

\author{
Timothy G. Laske • Henry J. Harlow • \\ David L. Garshelis • Paul A. Iaizzo
}

Received: 9 October 2009 /Accepted: 22 March 2010/Published online: 1 May 2010

(C) Springer Science+Business Media, LLC 2010

\begin{abstract}
American black bears survive winter months without food and water while in a mildly hypothermic, hypometabolic, and inactive state, yet they appear to be able to return to near-normal systemic function within minutes of arousal. This study's goal was to characterize the cardiovascular performance of overwintering black bears and elicit the underlying mechanisms enabling survival. Midwinter cardiac electrophysiology was assessed in four wild black bears using implanted data recorders. Paired data from early and late winter were collected from 37 wild bears, which were anesthetized and temporarily removed from their dens to record cardiac electrophysiological parameters (12-lead electrocardiograms) and cardiac dimensional changes (echocardiography). Left ventricular thickness, primary cardiac electrophysiological parameters, and cardiovascular response to threats ("fight or flight" response) were preserved throughout winter. Dramatic respiratory sinus arrhythmias were recorded (cardiac cycle length variations up to $865 \%$ ) with
\end{abstract}

\author{
T. G. Laske $\cdot$ P. A. Iaizzo $(\square)$ \\ University of Minnesota, \\ B172 Mayo, MMC 195, 420 Delaware St. SE, \\ Minneapolis, MN 55455, USA \\ e-mail: iaizz001@umn.edu \\ T. G. Laske \\ Medtronic, Inc., \\ 8200 Coral Sea St. NE, \\ Mounds View, MN, USA \\ H. J. Harlow \\ University of Wyoming, \\ BioSciences Bldg., Room 406, PO Box 3166, Laramie, WY, USA \\ D. L. Garshelis \\ Minnesota Department of Natural Resources, \\ 1201 E. Highway 2, \\ Grand Rapids, MN, USA
}

long sinus pauses between breaths (up to $13 \mathrm{~s}$ ). The accelerated heart rate during breathing efficiently transports oxygen, with the heart "resting" between breaths to minimize energy usage. This adaptive cardiac physiology may have broad implications for human medicine.

Keywords Black Bear Hibernation · Cardiac Physiology · Echocardiography Electrophysiology .

Implanted Data Recorders

\section{Introduction}

Typically, small mammalian hibernators survive the winter in secluded burrows where risks of predation are minimal, and they enter a state of severe hypothermia $\left(5-10^{\circ} \mathrm{C}\right)$ with bouts of complete arousal from overwintering every 10 15 days [8]. In contrast, American black bears (Ursus americanus) endure the winter months in a condition of starvation, dehydration, mild hypothermia, hypotension, and inactivity without bouts of active arousal. Due to their large body mass, black bears can settle in partially exposed dens with associated higher risks for predation and/or external disturbance [11, 21]. Although bears have depressed metabolic function during this period, we have observed defensive posturing and high respiratory rates in these animals within a very short period (seconds) of being disturbed. Because of this elevated level of arousal readiness and associated physiology that distinguishes bears from other hibernators, some avoid referring to the overwintering state exhibited by bears as "true" hibernation, whereas bear biologists generally accept it as such [14]. In this paper, we use the terms "hibernation" and "overwintering" synonymously in reference to the winter physiological state of mild hypothermia, hypotension, and hypometabolism in bears. 
The induction of a similar "hibernation-like" state in humans has been proposed for medical treatment and/or prolonged space travel [9]. Clinical applications of a reduced metabolic state typical of overwintering bears include treatment for human heart failure, stroke, myocardial infarction, and extending the duration of whole organ ischemia prior to transplantation [4]. We previously demonstrated that bears have limited loss of skeletal muscle protein and strength during winter, which has applications in preventing muscle disuse atrophy [12, 23, 37]. It is also advantageous to conserve cardiac muscle to maintain sufficient perfusion of all body tissues during winter and to enable a response to predatory threats. Ideally, the hearts of hibernating bears would have reduced energy expenditures during overwintering and also be capable of rapid arousal in the event of a threat - the "fight or flight" response regulated by the autonomic nervous system.

Atrophic remodeling of the human heart is commonly associated with disease and unloading by mechanical devices such as left ventricular assist devices (LVADs) and cardiopulmonary bypass pumps $[10,32]$. Decreases in cardiac mass as well as electrophysiological changes have also been observed in healthy humans during periods of prolonged inactivity and/or during space travel $[29,30,36]$. Although it has been reported that circulating proteins such as "hibernation induction trigger" and "hibernation-specific protein" complex (HPc) may play an important role in conserving cardiac form and function in hibernating mammals, the physiological mechanisms of the heart that aid in the prevention of ischemic tissue damage during overwintering have not been fully characterized $[3,16,18]$.

A previous assessment of three black bears, two grizzly bears (Ursus arctos), and two polar bears (Ursus mariti$m u s$ ) identified a reduction in heart rates as they entered the winter months [6]. In addition, studies of cardiac performance in captive subadult grizzly bears $(n=4)$ showed a decrease in heart rate and myocardial contractility, an increase in duration of the PQ interval, QRS, and QT interval, and a decrease in ventricular mass from the summer active to overwintering period [26, 27]. These researchers reported that grizzlies exhibit titin isoform switching during hibernation, stiffening the ventricles and likely reducing chamber dilation during the hypotensive conditions encountered during overwintering. To date, little research has been performed on the mechanisms driving these changes; moreover, no analogous research has been conducted on overwintering wild bears or on American black bears. Furthermore, previous research did not investigate whether cardiac changes occur during the winter months in these animals.

In this report, we describe novel findings on autonomic modulation of heart rate and respiratory function that may underlie the aforementioned adaptive advantages of the hibernating black bear. Specifically, we performed a comprehensive evaluation of cardiac structure and performance during overwintering in a large sample of free-ranging black bears with a focus on: (1) recording the natural cardiac activity during overwintering; (2) comparing cardiac dimensions and electrical function from early to late winter to determine if electrical and/or structural remodeling occurred; and (3) evaluating whether or not the "fight or flight" ability is preserved over the winter months of prolonged inactivity.

\section{Methods}

We performed a multi-year study on free-ranging American black bears during periods of early denning (NovemberDecember, 1-2 months after they entered dens for hibernation) and late denning (late-February-early-March, 0.5-1 month before their emergence from dens) in Colorado, Wyoming, and northern Minnesota. Animals were tracked to den sites via signals from their VHF telemetry radio collars, anesthetized (Telazol ${ }^{\circledR} ; 4.4 \mathrm{mg} / \mathrm{kg}$ ) using a syringe mounted on a jab pole or with a $\mathrm{CO}_{2^{-}}$ powered plastic dart (Dan-inject, Børkop, Denmark), then temporarily removed from their dens to assess their general health status and to perform the various measurements described below. These studies conformed to the Guide for Care and Use of Laboratory Animals (NIH). Furthermore, all studies were conducted in conjunction with the state natural resource agencies in Colorado, Wyoming, and Minnesota and were approved by Animal Care and Use Committees of the Universities of Wyoming and Minnesota.

The cardiovascular performance of overwintering black bears was assessed using three principal modalities: (1) mid-winter cardiac electrophysiology was assessed using implanted data recorders (IDRs); (2) early and late winter cardiac electrophysiological parameters were recorded using a 12-lead electrocardiogram; and (3) cardiac dimensional changes were evaluated using transthoracic echocardiography. Due to the paired nature of the latter two datasets, all statistical analyses were performed using a two-tailed Student's $t$ test for unequal variances with $\alpha=0.05$. Normality was tested using the Shapiro-Wilk $W$ test with $p>0.05$ at a $95 \%$ confidence level. Data were excluded as outliers if more than three standard deviations from the mean.

\section{Data Recorders}

During early winter 1999 and 2000, radio-collared wild bears were located in their winter dens, anesthetized with Telazol $^{\circledR}$, and temporarily extricated from their dens $[12,37]$. Customized IDRs and sensing leads (model 6942; Medtronic, Inc., Minneapolis, MN) were surgically implanted in early winter using aseptic techniques. The IDRs were 
designed to collect both wideband electrical data and acceleration. Implanted leads were connected to the IDRs and electrical signals were viewed using a software interface to ensure that the position of the electrodes provided an acceptable electrocardiogram (ECG). Electrodes were placed either subcutaneously in the pectoral region or intraperitoneally near the diaphragm. The IDRs were programmed to initiate data collection 21 days post-implant to minimize effects of the surgical procedure on behavior and physiology. Data were collected for 30 -s periods every 15 min during the winter months. Additionally, intraperitoneal temperatures were recorded (StowAway ${ }^{\circledR}$ TidbiT ${ }^{\mathrm{TM}}$ temperature loggers, Onset, Bourne, MA). Follow-up visits to the den sites were made during March to retrieve the devices. The device design and implant methodology are detailed elsewhere [19].

In the analyses of the electrical signals from the IDRs, respiratory sinus arrhythmia (RSA) was defined as a variation in heart rate associated with the respiratory cycle. RSA was quantified as the percent change from minimum to maximum heart rate using the peak-trough method [31].

\section{2-Lead Electrocardiography}

Electrocardiographic performance of each bear's heart was assessed using a 12-lead ECG (LIFEPAK ${ }^{\circledR} 12$ electrophysiology unit, Medtronic, Inc.). Bears were first anesthetized (Telazol ${ }^{\circledR}, 4.4 \mathrm{mg} / \mathrm{kg}$ ), removed from their dens, measured, and weighed on a hanging spring scale. ECG limb electrodes were attached in the pectoral and femoral regions, and precordial electrodes were attached in the intercostal space superior to the palpable apex of the heart from the peristernal region to the axilla (precordial leads V2-V6) and on the right side of the sternum (V1). Prior to electrode attachment, fur was trimmed and shaved, and the skin was abraded and cleaned with alcohol and gauze pads to provide acceptable electrical contact by the electrodes. Recordings were taken while the animal was adequately anesthetized and positioned supine. Values for the QT intervals were corrected (QTc) for heart rate (HR) using the following formulas:

$$
\begin{aligned}
& \mathrm{QTc}_{\text {Bazett }}=\mathrm{QT} /\left((60 / \mathrm{HR})^{1 / 2}\right) \\
& \mathrm{QTc}_{\text {Fridericia }}=\mathrm{QT} /\left((60 / \mathrm{HR})^{1 / 3}\right)
\end{aligned}
$$

\section{Echocardiography}

Immediately following 12-lead electrophysiological assessment, cardiac images were collected using a portable ultrasound unit (Acuson Cypress ${ }^{\mathrm{TM}}$, Siemens, Inc., Deerfield, IL). The transthoracic echocardiography probe was positioned in the same shaved region used for the precordial ECG electrodes. Short-axis (apical, mid-papillary, basal) and long- axis views were obtained of the left ventricle using M-mode imaging while the animal was in a left lateral recumbent posture. Measurements focused on the left ventricular wall thickness for comparison with previous clinical and bear research and also to provide the highest signal-to-noise ratio (wall thickness vs. echocardiographic resolution). Echocardiographic analyses were performed with the operator blinded to both the date of image collection and animal identification.

The average left ventricular wall thickness was calculated from four orthogonal measurements on a short-axis section near the middle of the papillary muscles. Comparisons were made between average left ventricular wall thickness obtained during early and late winter for both systole and diastole. We posited that wall thickness could vary with changes in the state of hydration of each bear, which we examined by measuring hematocrit of blood drawn from a femoral vein.

\section{Results}

Most bears studied in Colorado, Wyoming, and Minnesota overwintered in enclosed dens, but a few larger males in Minnesota used open ground nests. In most cases, these animals were aware of our presence when we approached to anesthetize them (typically from 1-2 $\mathrm{m}$ away); their responses ranged from slowly lifting their heads to swatting and defensive posturing from within the den. Two dens typical of those used by Minnesota bears are shown in Fig. 1. The bears pictured were alert upon our arrival, as evidenced by the photographs and corresponding infrared images.

The initial mass of the Colorado and Wyoming sample bears ( $n=4$ females without cubs) ranged from 64 to $79 \mathrm{~kg}$. They lost $21.6 \pm 7.4 \%$ of their mass $(0.15 \pm 0.06 \mathrm{~kg} /$ day $)$ from early to late winter. The larger Minnesota bear sample ( $n=37$, including both sexes and various ages) was more variable in initial mass (range, $20-218 \mathrm{~kg}$ ). Their body mass during our late winter examination decreased by an average of $11.9 \pm 5.5 \%$ (range, $18-187 \mathrm{~kg}$ ), which was less than the Colorado and Wyoming sample because the span between our visits was less. Average daily mass loss of Minnesota bears between early and late winter $(0.15 \pm$ $0.12 \mathrm{~kg} /$ day; range, $0.02-0.49 \mathrm{~kg} /$ day) was similar to bears in Colorado and Wyoming. All adult females in Minnesota either denned with their 1-year-old offspring from the previous year (some of which were part of the study sample) or were pregnant during our early winter examination and gave birth prior to our late winter examination (black bear cubs are typically born in January).

\section{Cardiac Activity During Overwintering}

Broadband electrical data were collected from IDRs in four bears denning in Colorado and Wyoming. The period of 

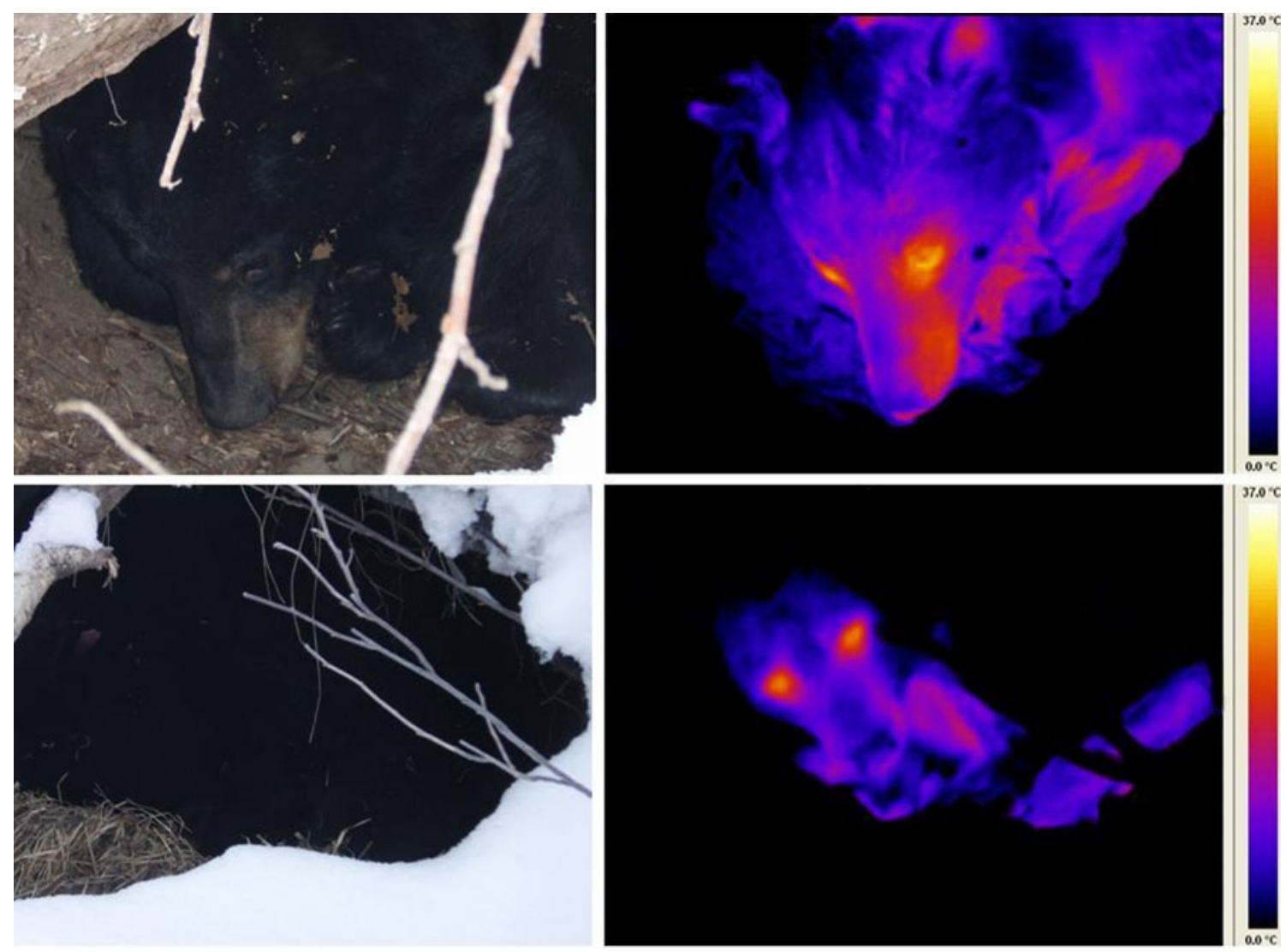

Fig. 1 Optical and infrared images of hibernating wild black bears. Images were taken upon arrival at two den sites in late December. Infrared images on the right are cropped to match the corresponding optical image at the left. Cardiac function is maintained during winter to enable "fight or flight" behavior. Infrared images $\left(0-37^{\circ} \mathrm{C}\right.$ color scale) clearly show that the bears are alert (eyes open). The fur

successful data collection ranged from 16 to 68 days [19]. The electrical data were used to construct ECGs, respiratory rates, and electromyograms. Respiratory cycles were identified by modulations of the QRS amplitudes (Fig. 2) $[15,25]$. Notched T-waves can be seen in Fig. 2 for bears 1 and 3. This morphology has been associated with long QT syndrome and with voltage gradients between myocardial layers; however, the underlying cause is unknown [17, 28].

The minimum recorded heart rate in the study was $4.5 \mathrm{bpm}$ (13-s sinus pause) in Bear 2; this bear averaged a heart rate of $13.5 \pm 3.8 \mathrm{bpm}$ over the 68 -day period (Fig. 3 and Table 1). The daily activity for this sample of bears was compared on the same day (February 5, 2000 and 2001). This date was selected as representative of a typical midwinter profile when all bears were recovered from the device implantation and deep within the overwintering cycle. The intraperitoneal temperatures ranged from $33.3^{\circ} \mathrm{C}$ to $36.7^{\circ} \mathrm{C}$, and the wideband data were collected for $30 \mathrm{~s}$ every $15 \mathrm{~min}$ (referred to as an "epoch;" $n=96$ per day). Results from the IDRs for this period are summarized in Table 1. Dramatic RSAs were recorded from each animal. substantially reduces heat loss, with the maximum temperatures recorded from the eyes (upper panel, $27.6^{\circ} \mathrm{C}$; lower panel, $24.7^{\circ} \mathrm{C}$ ). Rectal temperatures for these animals were also recorded immediately upon removal from the den and just prior to return to the dens (upper panel, $38.4^{\circ} \mathrm{C}$ at $4: 15$ P.M. and $36.1^{\circ} \mathrm{C}$ at 5:40 P.M.; lower panel, $36.8^{\circ} \mathrm{C}$ at 9:39 A.M. and $35.9^{\circ} \mathrm{C}$ at $10: 37$ A.M.)

Heart rate for the 24-h period (Fig. 4) exhibited striking changes that corresponded with inspiration. The average change in cardiac cycle length for this 24 -h period ranged (among the four bears) from $121 \%$ to $299 \%$. The single greatest change in cycle length recorded within a 30 -s epoch was $865 \%$ for Bear $2(1.01-9.73 \mathrm{~s}$ increase in cycle length, equating to an increase in heart rate from 6.2 to $59.4 \mathrm{bpm})$. Increased heart rates were also associated with periods that included electromyographic activity (EMGs were used to deduce periods of activity vs. inactivity).

In addition to 12-lead ECG data, the IDR signal from Bear 2 enabled measurement of QRS width and QT duration throughout the undisturbed 68-day recording interval (data shown in Fig. 5). Importantly, no significant changes were observed in any parameter when the initial and final intervals were compared for this animal. Bear 2 had a short QT interval even at an average rate of only $13 \mathrm{bpm}$. The corrected value $\left(\mathrm{QTc}_{\mathrm{Bazett}}\right)$ averaged $0.164 \pm 0.22 \mathrm{~s}$, indicating that the rate dependence is lost in this situation (the typical corrected value for humans is $0.42 \mathrm{~s})$. 


\section{Bear 1}
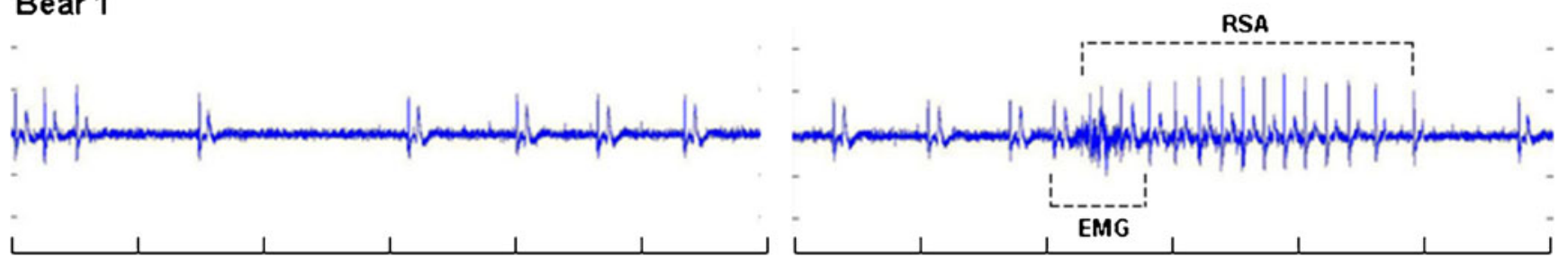

\section{Bear 2}
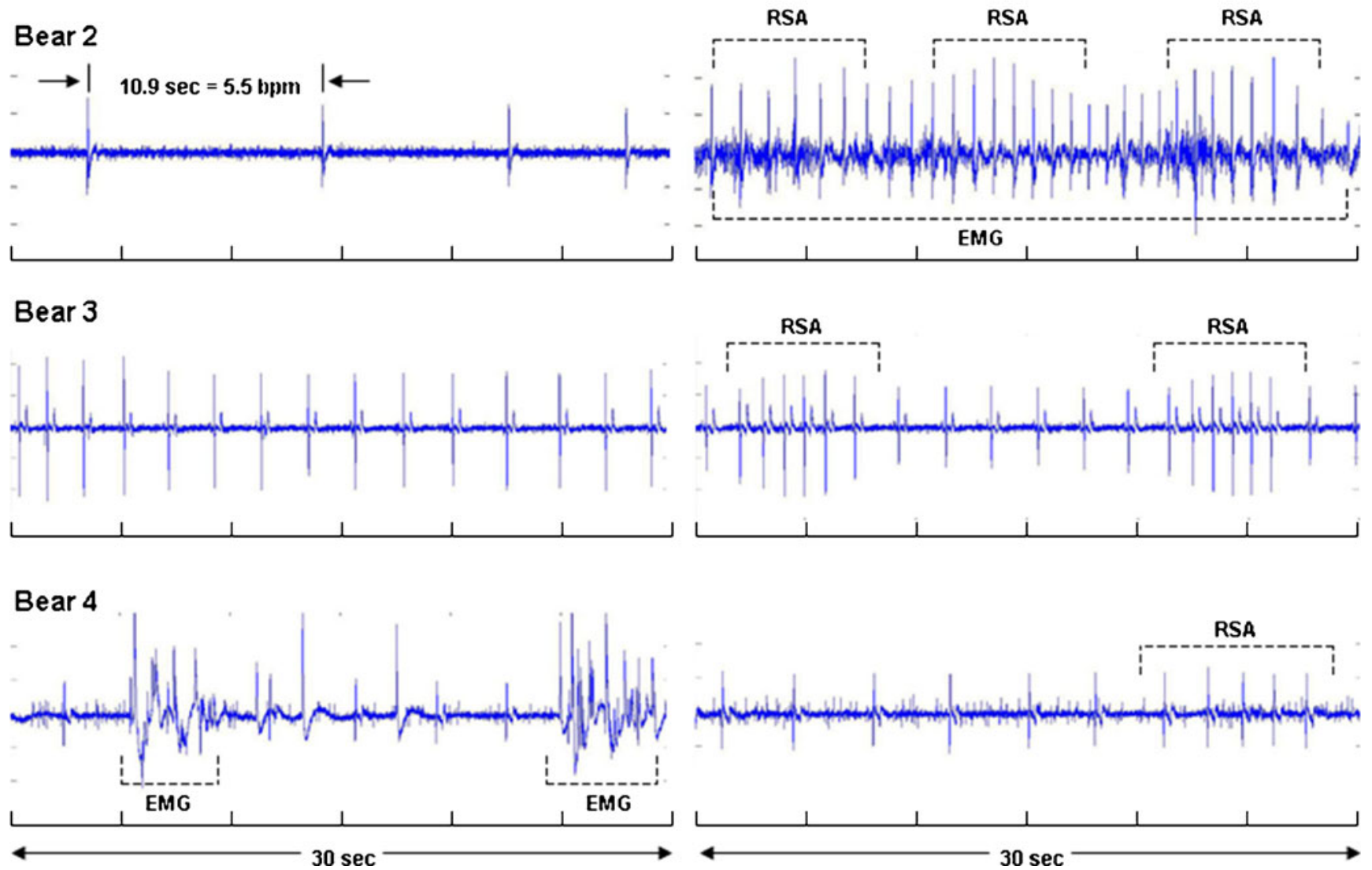

Fig. 2 Electrocardiograms from hibernating wild black bears. Thirtysecond traces with low heart rates (left) and respiratory sinus arrhythmias (RSA, right) are shown for four different bears. Electrical data were captured with implanted data recorders during mid-winter. RSAs were seen in all animals and were identified by an increase in heart rate and a modulation of the electrogram amplitude corresponding

with chest expansion and relaxation. The respiration rates that elicited the RSA identified in the right panels for Bears 1-4 are two, six, four, and two breaths/minute, respectively. Electromyographic activity $(E M G)$ is noted in the right epochs for Bears 1 and 2 and the left epoch for Bear 4

Cardiac Preservation: Cardiac Electrophysiology

Thirty paired datasets were collected from the 37 bears studied in Minnesota ( 9 males, 21 females; age range, 115 years, $\bar{x}, 5.2$ years) using 12-lead ECGs during early and late winter, 2002 to 2007 ( $\bar{x}$ time between handlings $=73.7 \pm$ 8.7 days; range, 52-87 days). A small but statistically significant change was observed for two of the eight measured electrophysiological parameters: (1) a decrease in recorded QRS widths $(6.9 \%$ decrease, $0.082 \pm 0.009$ vs. $0.076 \pm 0.009 \mathrm{~s}, p=0.020)$ and (2) corrected QT intervals $\left(\mathrm{QTc}_{\mathrm{Bazett}}, 4.1 \%\right.$ decrease; $0.423 \pm 0.022$ vs. $0.405 \pm 0.021 \mathrm{~s}$,

$p=0.003 ; \mathrm{QTc}_{\text {Fridericia }}, 4.4 \%$ decrease; $0.380 \pm 0.025$ vs. $0.363 \pm 0.022 \mathrm{~s}, p=0.007)$. Detailed results from the 12-lead electrocardiography are shown in Table 2. All collected data were used in the analyses with the exception of one late winter P-wave duration of $0.203 \mathrm{~s}$, which was excluded as an outlier.

Notched T-waves were also seen in the Minnesota bear sample ( 3 of 30 bears in early winter, 2 of 30 animals in late winter). A number of bears in Minnesota also exhibited notched QRS complexes ( 10 of 30 animals in early winter, 15 of 30 bears in late winter; Fig. 6). This morphology is similar to what would be seen with an interchamber conduction 
Fig. 3 Heart rate of a wild black bear during hibernation for the 68-day period from December 31, 2000 to March 8, 2001 (Bear 2 with implanted data recorder). Data were collected for $30 \mathrm{~s}$ every $15 \mathrm{~min}$ in each 24 -h period $(n=96$ epochs/day; 6,240 total epochs). For each day, the average heart rate, maximum and minimum rate averaged over the 96 epochs, and absolute maximum and minimum heart rate are shown. Error bars, 1 standard deviation
Daily Heart Rates Recorded in a Hibernating Black Bear (Bear 2; 31-Dec-2000 to 8-Mar-2001; 30 second data samples every 15 minutes)

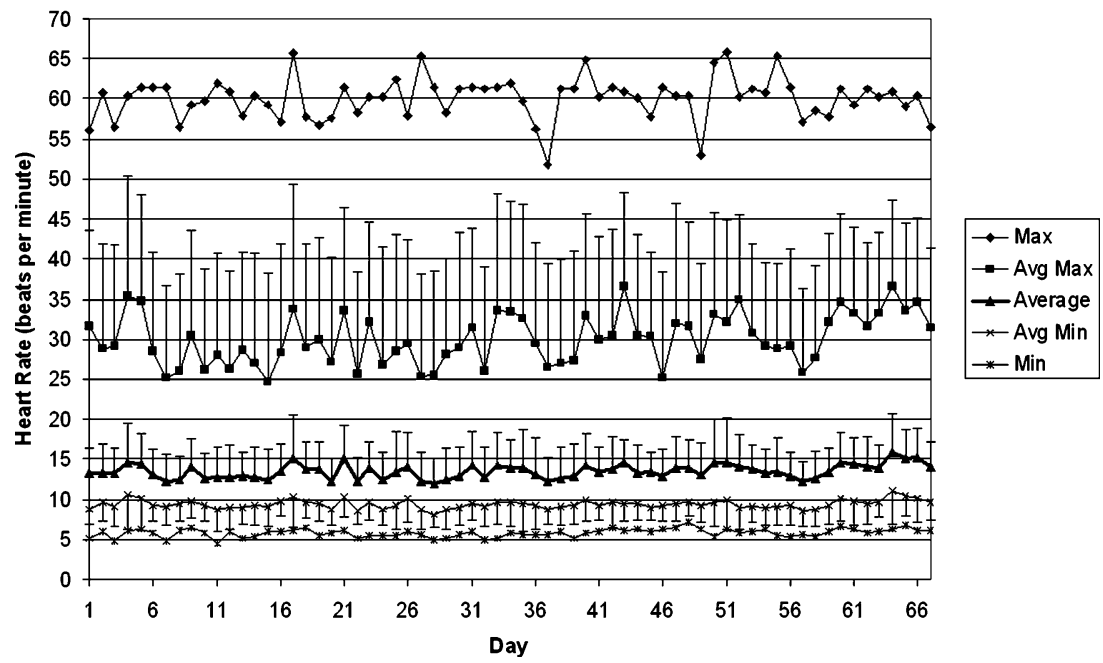

delay, such as a bundle branch block. The cause of notching in the bears is unknown, but may be related to ventricular size or anesthesia.

\section{Cardiac Preservation: Cardiac Structure}

Thirty-seven paired datasets (10 males, 27 females; age range, 1-15 years) were collected from bears in Minnesota using echocardiography during early and late winter, 2001 to 2007 ( $\bar{x}$ time between handlings $=75.1 \pm 8.9$ days; range, 52-97 days). No significant differences were observed in left ventricular dimensions between early and late denning periods. The average wall thickness during diastole and systole was unaltered between early and late winter (Fig. 7). Left ventricular wall thickness in diastole for the entire sample was $1.53 \pm 0.42 \mathrm{~cm}$ in early hibernation and $1.44 \pm 0.39 \mathrm{~cm}$ in late hibernation $(p=0.34)$. Left ventricular wall thickness in systole for the entire sample was $1.82 \pm 0.55 \mathrm{~cm}$ in early

Table 1 Heart rate data recorded from implanted data recorders in hibernating wild black bears in Colorado and Wyoming

\begin{tabular}{|c|c|c|c|c|c|}
\hline & $\begin{array}{l}\text { Bear } 1 \\
(05-F e b-01)\end{array}$ & $\begin{array}{l}\text { Bear } 2 \\
(05-F e b-01)\end{array}$ & $\begin{array}{l}\text { Bear } 3 \\
(05-\text { Feb-00) }\end{array}$ & $\begin{array}{l}\text { Bear } 4 \\
(05-F e b-00)\end{array}$ & $\begin{array}{l}\text { Bear } 2 \\
\text { (Winter 2001) }\end{array}$ \\
\hline Interval & $24 \mathrm{~h}$ & $24 \mathrm{~h}$ & $24 \mathrm{~h}$ & $24 \mathrm{~h}$ & 68 days \\
\hline $\begin{array}{l}\text { Core body temperature } \\
\left({ }^{\circ} \mathrm{C} ; \mathrm{max} / \mathrm{min}\right)\end{array}$ & $33.6 \pm 0.27(34.3 / 33.1)$ & $33.3 \pm 0.50(34.0 / 33.4)$ & $36.7 \pm 0.47(37.4 / 35.9)$ & $34.9 \pm 0.19(35.0 / 34.7)$ & - \\
\hline Average heart rate (bpm) & $20.3 \pm 5.7$ & $13.1 \pm 6.6$ & $38.8 \pm 8.5$ & $24.6 \pm 4.5$ & $13.5 \pm 3.8$ \\
\hline Max CL (s) & 8.4 & 10.8 & 2.5 & 4.8 & 13.3 \\
\hline Min CL (s) & 0.79 & 0.79 & 0.61 & 0.95 & 0.91 \\
\hline Avg max CL (s) & $5.6 \pm 1.5$ & $7.2 \pm 1.9$ & $1.9 \pm 0.28$ & $3.6 \pm 0.62$ & $6.8 \pm 1.5$ \\
\hline Avg min CL (s) & $1.5 \pm 0.39$ & $2.9 \pm 1.6$ & $0.89 \pm 0.17$ & $1.5 \pm 0.34$ & $2.6 \pm 1.5$ \\
\hline $\begin{array}{l}\text { Significance of max vs. } \\
\text { min CL }\end{array}$ & $p<0.001$ & $p<0.001$ & $p<0.001$ & $p<0.001$ & - \\
\hline Variation in CL (\%) & $299 \pm 136$ & $215 \pm 152$ & $121 \pm 30$ & $153 \pm 62$ & $227 \pm 145$ \\
\hline Max CL variation (range in s) & $733 \%(0.79-6.6)$ & $525 \%(1.6-10.2)$ & $180 \%(0.7-1.9)$ & $271 \%(0.95-3.6)$ & $865 \%(1.0-9.7)$ \\
\hline $\begin{array}{l}\text { Avg HR without EMG } \\
\text { present (bpm) }\end{array}$ & $17.6 \pm 2.3$ & $11.7 \pm 2.3$ & $36.8 \pm 4.8$ & $22.8 \pm 2.4$ & - \\
\hline $\begin{array}{l}\text { Avg HR with EMG present } \\
\text { (bpm) }\end{array}$ & $24.2 \pm 7.0$ & $26.4 \pm 13.8$ & $46.3 \pm 14.0$ & $26.1 \pm 5.3$ & - \\
\hline $\begin{array}{l}\text { Significance of avg HR } \\
\text { with vs. without EMG }\end{array}$ & $p<0.001$ & $p<0.001$ & $p=0.007$ & $p=0.001$ & - \\
\hline $\begin{array}{l}\text { HR increase when EMG } \\
\text { present }(\%)\end{array}$ & 37 & 126 & 26 & 14 & - \\
\hline Epochs with EMG activity (\%) & 43.2 & 10.6 & 20.8 & 64.6 & - \\
\hline
\end{tabular}

Data were collected in 30-s intervals every $15 \mathrm{~min}$ (96 epochs/day). All heart rates are reported in beats per minute

$A v g$ average, $b p m$ beats per minute, $C L$ cardiac cycle length, $H R$ heart rate, max maximum, min minimum 


\section{Bear 1}

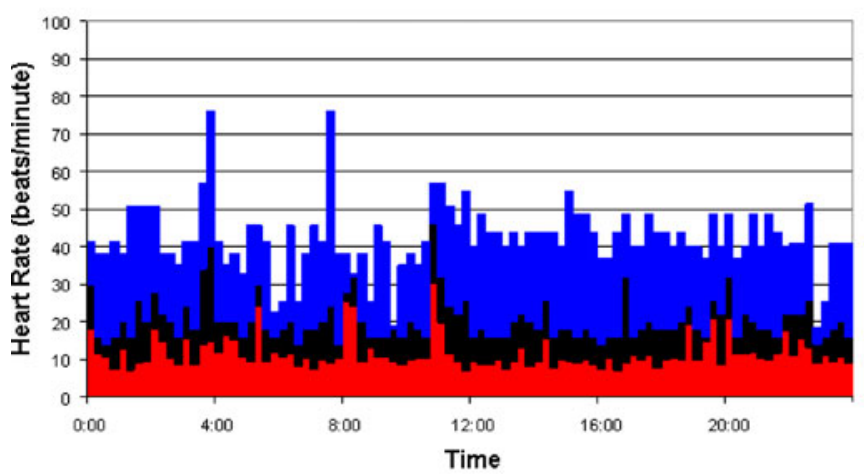

Bear 3

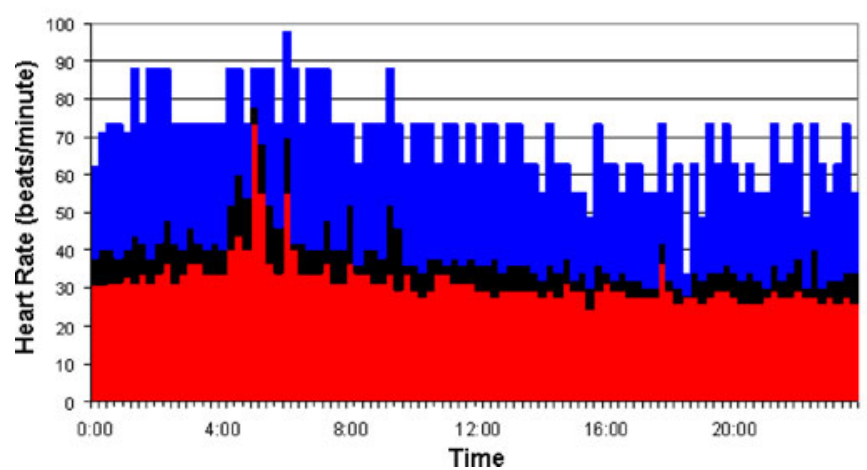

Fig. 4 Daily heart rate variability of four wild hibernating black bears implanted with data recorders: minimum (red), average (black), and maximum (blue) rates for each 15-min period throughout the day for one selected day in mid-winter (Bears 1 and 2: February 5, 2001;

hibernation and $1.73 \pm 0.53 \mathrm{~cm}$ in late hibernation $(p=0.48)$. Left ventricular wall thickness in diastole for the pregnant females $(n=7)$ was $1.72 \pm 0.27 \mathrm{~cm}$ in early hibernation and $1.45 \pm 0.22 \mathrm{~cm}$ in late hibernation $(p=0.068)$, after they had given birth. Left ventricular wall thickness in systole for the pregnant females $(n=7)$ was $1.86 \pm 0.31 \mathrm{~cm}$ in early hibernation and $1.58 \pm 0.32 \mathrm{~cm}$ in late hibernation $(p=0.12)$. The data were also analyzed when normalized for animal size using

\section{Bear 2}

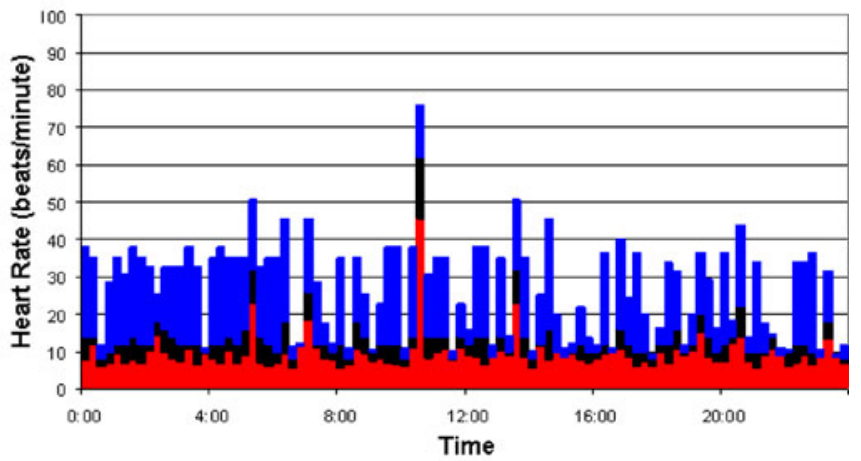

Bear 4

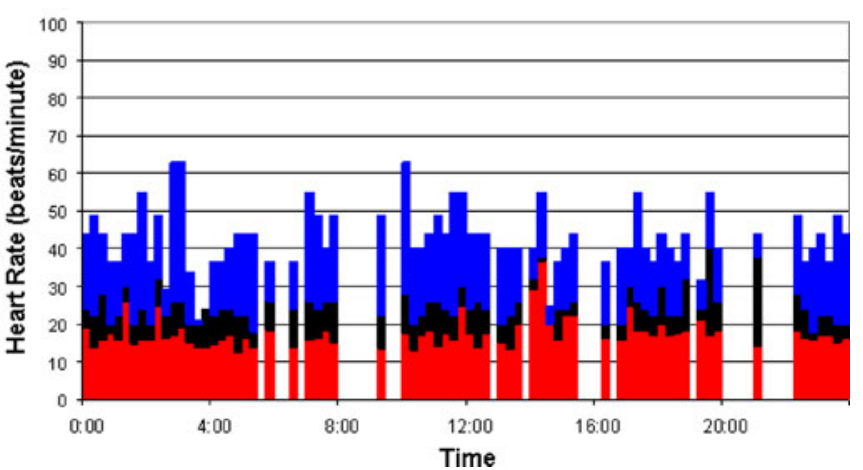

Bears 3 and 4: February 5, 2000). The heart rate data for Bear 4 was lost in certain epochs due to an overwhelming electromyographic signal

bear mass in early winter, with no significant decrease in wall thickness detected.

Average hematocrit values for early and late winter for the entire Minnesota sample did not vary $(43.3 \pm 7.9 \%$ and $43.9 \pm$ $4.7 \%$, respectively, $p=0.72$ ). However, average hematocrit for the subgroup of pregnant females $(n=7)$ increased an average of $27 \%$ (from $37.0 \pm 5.0 \%$ to $47.0 \pm 1.9 \%, p=0.001$ ) after they gave birth. Low hematocrit in early winter for
Fig. 5 Cardiac electrophysiological parameters of a wild hibernating black bear. Graph shows the average daily QRS width and QT interval extracted from the implanted data recorder for Bear 2 (68 days).

Overwintering averages for the parameters were: $\mathrm{QRS}=0.073 \pm$ $0.008, \mathrm{QT}=0.347 \pm 0.045 \mathrm{~s}$, $\mathrm{QTc}_{\text {Fridericia }}=0.211 \pm 0.027$, and $\mathrm{QTc}_{\text {Bazett }}=0.164 \pm 0.022 \mathrm{~s}$
Electrogram Characteristics for a Hibernating Black Bear (Bear 2; Average values; 30 second sample every 15 minutes)

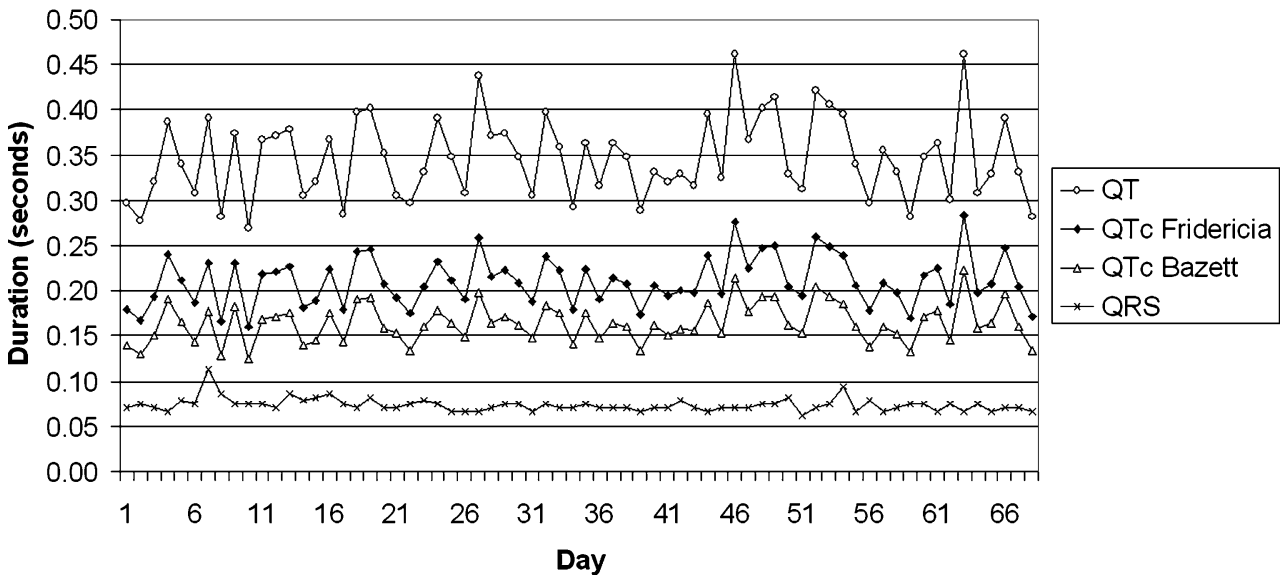


Table 2 Cardiac electrophysiological data recorded during den visits to hibernating wild black bears in Minnesota in early (December) and late winter (late February-early March)

\begin{tabular}{|c|c|c|c|c|}
\hline & Early Winter & Late Winter & Change (\%) & $p$ value \\
\hline Heart rate $(\mathrm{bpm})$ & $115.5 \pm 17.1(65-152)$ & $117.6 \pm 17.7(75-141)$ & +1.8 & N.S. $(0.64)$ \\
\hline PR interval (s) & $0.134 \pm 0.017(0.108-0.176)$ & $0.126 \pm 0.018(0.100-0.174)$ & -5.8 & N.S. (0.096) \\
\hline P-wave duration (s) & $0.111 \pm 0.018(0.069-0.139)$ & $0.104 \pm 0.018(0.057-0.135)$ & -6.4 & N.S. $(0.15)$ \\
\hline QRS width (s) & $0.082 \pm 0.009(0.068-0.102)$ & $.076 \pm 0.009(0.060-0.092)$ & -6.9 & 0.020 \\
\hline QT interval (s) & $0.308 \pm 0.035(0.238-0.414)$ & $0.292 \pm 0.029(0.240-0.368)$ & -5.1 & N.S. $(0.065)$ \\
\hline $\mathrm{QTc}_{\text {Bazett }}(\mathrm{s})$ & $0.423 \pm 0.022(0.367-0.465)$ & $0.405 \pm 0.021(0.347-0.439)$ & -4.1 & 0.003 \\
\hline $\mathrm{QTc}_{\text {Fridericia }}(\mathrm{s})$ & $0.380 \pm 0.025(0.318-0.428)$ & $0.363 \pm 0.022(0.309-0.396)$ & -4.4 & 0.007 \\
\hline T-wave duration (s) & $0.195 \pm 0.057(0.075-0.274)$ & $0.185 \pm 0.051(0.072-0.256)$ & -5.2 & N.S. $(0.48)$ \\
\hline
\end{tabular}

These data were taken after the animals were approached (often aroused to some degree), anesthetized, and removed from their dens. Data are presented as average \pm 1 standard deviation (maximum value - minimum value)

bpm beats per minute, N.S. not significant

pregnant females is consistent with the increased retention of fluid required to support mid-winter lactation. Pregnant females were analyzed separately to ascertain whether ventricular wall thickness varied with decreased interstitial fluid volume during overwintering; again, no statistically significant changes in cardiac structure were detected.

\section{Discussion}

We showed that overwintering black bears conserve cardiac tissue form and function, thus retaining the ability to respond to external threats. This is enabled by a profound

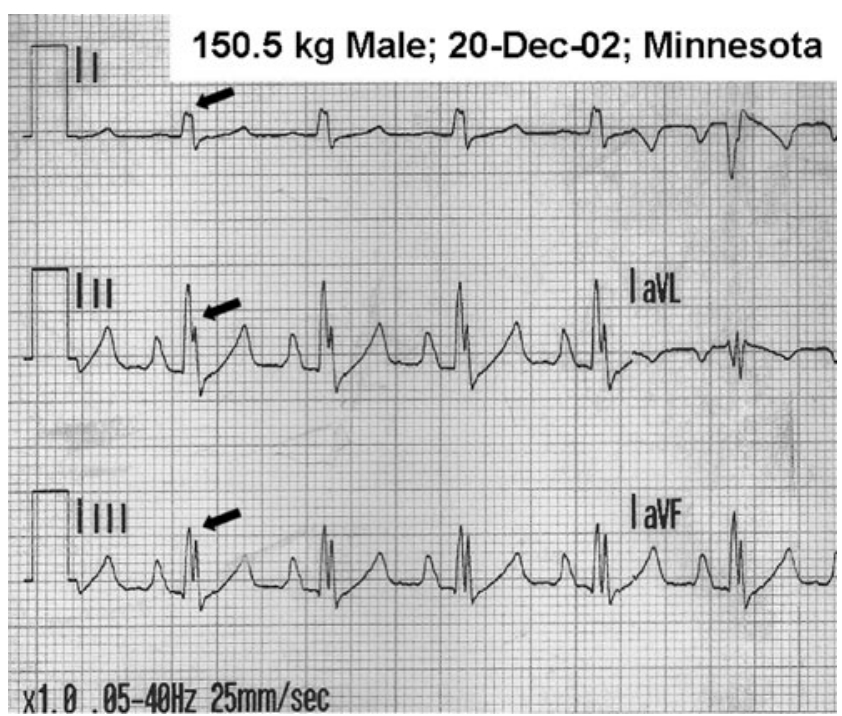

Fig. 6 Traces from leads I-III of an electrocardiogram from a hibernating wild black bear (150 kg male) in Minnesota. A notch can clearly be seen in the QRS as indicated by the black arrows. This pattern, which is similar to a bundle branch block, was a common finding in the Minnesota sample. Heart rate $=97 \mathrm{bpm} ; \mathrm{PR}=0.152 \mathrm{~s}$; QRS width $=0.110 \mathrm{~s}$, and QT $=0.346 \mathrm{~s}$ modulation of heart rate, resulting in the lowest transient heart rates recorded for a relatively normothermic land mammal (sinus pauses up to $13 \mathrm{~s}$, equivalent to $4.5 \mathrm{bpm}$ ). We believe that the pervasive adaptive feature for preservation of cardiac performance in the overwintering black bear is this dramatic modulation of heart rate. Although humans also exhibit RSAs, the magnitude of RSAs in these hibernating bears is more than an order of magnitude greater: $20 \%$ for humans under normal conditions [1] vs. up to $865 \%$ in hibernating bears. The RSA has been recognized as a measure of activity of the parasympathetic nervous system $[2,31]$. Whether this is the system driving the RSA in bears is unknown; it may be modulated by lung-based mechanoreceptors, intrapleural pressure, and/or another unidentified mechanism.

Another hibernator with a well-documented RSA is the golden-mantled ground squirrel (Spermophilus lateralis). However, in this animal, the RSA diminishes as their body temperature drops during hibernation, with a $108 \%, 32 \%$, and $11 \%$ increase in heart rate reported with each breath at $15^{\circ} \mathrm{C}, 10^{\circ} \mathrm{C}$, and $5^{\circ} \mathrm{C}$, respectively [13]. The RSA we observed in hibernating black bears differs in both magnitude and the body temperature at which it occurs. We discerned no relationship between intraperitoneal body temperatures in these bears and either the magnitudes of their RSAs or average heart rates, perhaps due to the stability of mid-winter body temperatures during the electrophysiological recording period (Table 1).

The long sinus pauses are likely also neurally enabled and modulated in order to avoid ectopic heartbeats emanating from the ventricular conduction system (atrioventricular node, bundle branches, and Purkinje fibers). In bats, cholinergic innervation appears to suppress such cardiac escape rhythms [24]. Whether the hearts of black bears are similarly innervated is unknown.

The black bear's conservation of cardiac form and function during prolonged inactivity is unlike what has 
Fig. 7 Lack of left ventricular remodeling by hibernating wild black bears. Top panel A typical cross-sectional echocardiographic image is shown. The left ventricular wall thickness $(n=4$ measurements for each section) was recorded in a blinded fashion on a mid-papillary muscle short-axis section. Bottom panel Plot of left ventricular wall thickness in early and late winter for the entire sample of Minnesota bears and for the subpopulation of females that gave birth

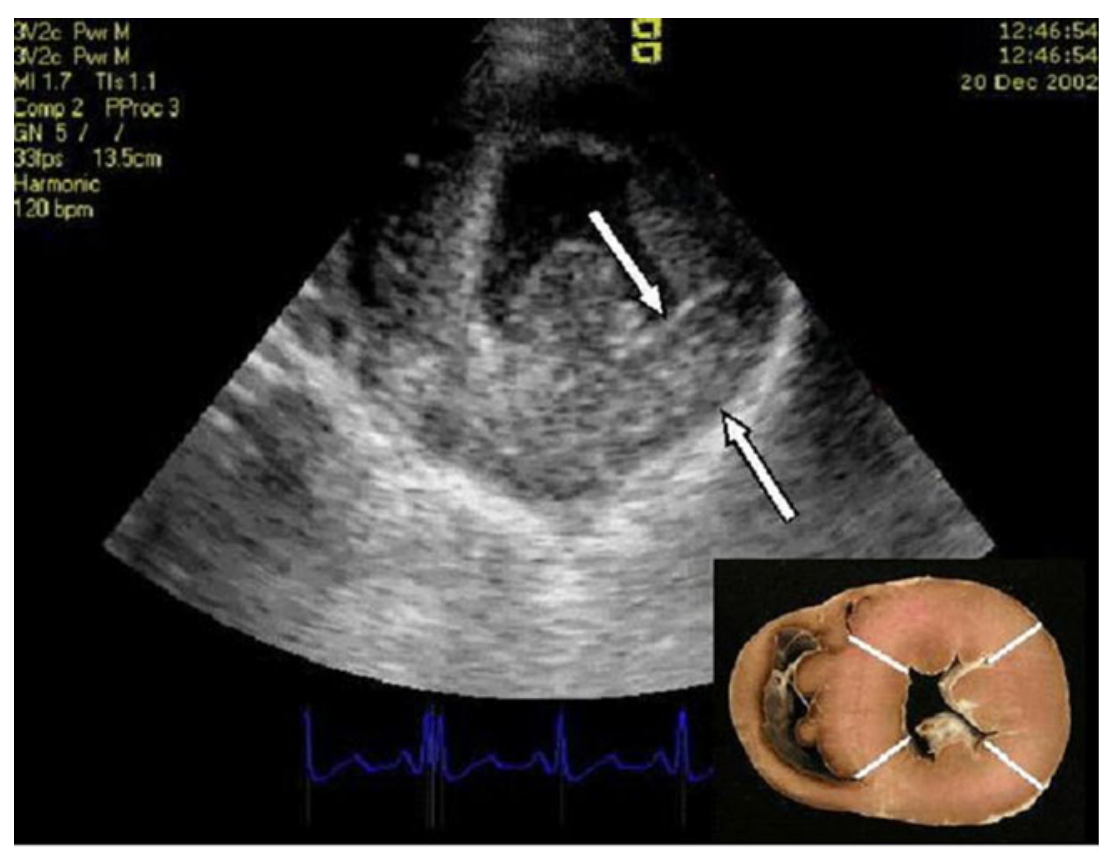

Average Left Ventricular Wall Thickness (Mid-Papillary Short Axis Section)

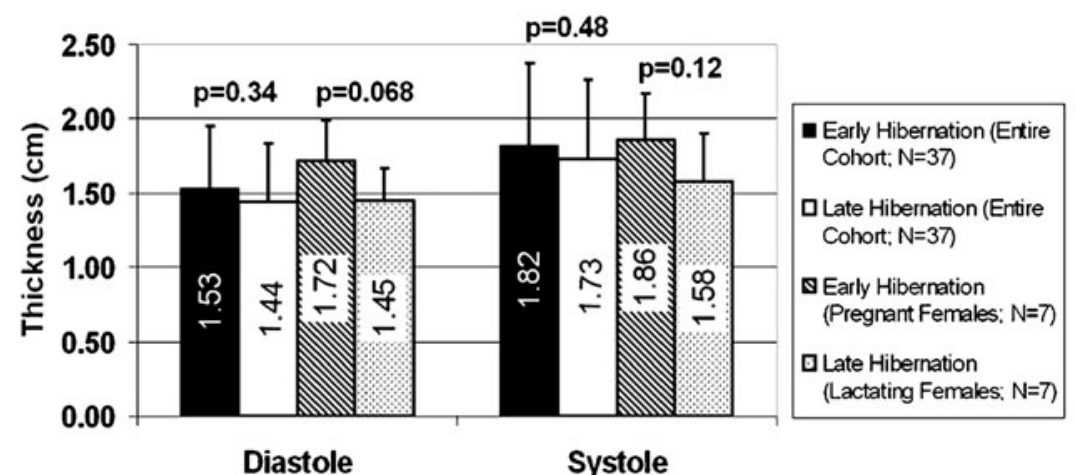

been observed for the human heart, which experiences significant remodeling within weeks of mechanical unloading due to hospitalization or during space travel $[20,29,30$, $35,36]$. For example, in a study of bedridden patients, 2 weeks of bed rest resulted in a $17 \%$ decrease in plasma volume and a probable decrease in cardiac mass [35]. Likewise, astronauts exposed to short durations of microgravity showed a $9.1 \%$ decrease in left ventricular mass, which notably returned to pre-flight values within 3 days. These data were interpreted to indicate that the changes were due to loss of myocardial interstitial fluid secondary to a loss in plasma volume [36]. Another study found that after 6 weeks of bed rest, the left ventricular mass decreased by $8 \%$ and left ventricular wall thickness decreased by $4 \%$, while after 10 days of space flight, the left ventricular mass decreased by $12 \%[29,30]$. The authors of this study proposed that these modifications resulted from physiological adaptations to reduced myocardial load and work. Such changes can also be viewed as an expression of myocardial atrophy. The lack of structural cardiac changes observed in our study of bears, which remained nearly motionless in dens for 5-7 months, is supported by other bear studies showing no increase in plasma alanine levels, the primary amino acid in cardiac tissue, during prolonged winter denning [22].

We believe that the electrophysiological changes seen in the QRS and QTc durations of hibernating bears are due to either a slight decrease in interstitial fluid volume attributed to posture, remodeling of cell membrane channel proteins, or chronic effects of mechanical unloading. These conclusions are supported by other findings in hibernating mammals and human clinical studies. Similar changes due to increased cardiac conduction velocities have been reported in the Siberian ground squirrel (Citellus undulatus) due to an upregulation of myocardial gap junction proteins (connexins) during winter hibernation [7]. Mechanical unloading due to mechanical LVADs has also been shown to cause an immediate decrease in QRS duration and a decrease in QTc with sustained support, with changes attributed to cardiac 
remodeling [10]. The changes that we observed were unrelated to hematocrit and therefore not likely due to dehydration. One potential limitation of the present study is that QT correction factors were applied to the data presented in Fig. 5 and Table 2. Due to the exceptionally low heart rates and heart rate variability, it is not known whether such corrections are appropriate for this mammal. Nevertheless, the inclusion of these corrections does not alter the overall trends in the data or the conclusions of this study.

Prior research on captive grizzly bears and a single black bear showed differences in cardiac form and function between summer active and hibernating bears [26, 33]. The changes included reduced cardiac mass, prolonged electrophysiological parameters, reduced cardiac output, and increased peripheral vascular resistance during hibernation. Our study showed that overwintering black bears conserve their cardiac tissue form and function from early to late winter. Combining the findings of these studies, we propose that the unique cardiovascular physiology seen in winter is likely a result of physiological changes in preparation for winter, as opposed to changes resulting from environmental stresses and prolonged hypotension during the winter months.

The mechanisms enabling black bears to survive winter immobility have many potential clinical applications. Our laboratory has previously shown that delta opioid agonists, which are considered to be a component of the hibernation induction trigger in black bears, reduce ischemia-reperfusion injury of both cardiac and skeletal muscle of non-hibernators $[16,34]$. Relative to the findings of the present study, the ability to induce extremely low heart rates without risking global ischemic damage or cardiac remodeling would be of value in numerous clinical scenarios and/or for long distance space travel. We believe that the inspiration-induced tachycardia (RSA) maintains cardiac muscle tone by periodically exercising the muscle and is an efficient means of transporting oxygen to cardiac and other tissues to prevent ischemia and to maintain alertness. The low heart rates and long sinus pauses between breaths may act to conserve energy, water, and Krebs cycle intermediates within the heart and thus reduce the need for cardiac protein catabolism. The advantage of this cardiac adaptation is to maintain the capacity for overall tissue perfusion to elicit a "fight or flight" response if disturbed and ultimately the capacity to emerge from hibernation with the ability for unimpaired activity.

Given that RSA with prolonged cardiac pauses, as observed in bears, can potentially conserve heart energy expenditure while breath-induced tachycardia maintains tissue perfusion, we suggest that a similarly enhanced RSA in humans could facilitate a prolonged hypothermic/ hypotensive state with minimal ischemia pathologies. This might have profound importance in a clinical surgical/ recovery setting and could be accomplished through the use of existing technologies to stimulate the vagus nerve in the interval between either naturally occurring or mechanically assisted inhalation/exhalation. The recent report of a hibernating primate lends support to the idea that most mammals have the genetic capacity to enter a form of metabolic hibernation under certain circumstances and with only minor physiological adjustments [5]. In addition, the increased respiratory sinus arrhythmia seen in patients suffering from seasonal affective disorder provides further encouragement in support of research to apply the bear's overwintering physiology to human medicine [1]. In summary, cardiac function might be restored or maintained in the clinical setting or during space travel through modulation and coordination of cardiac and respiratory function to mimic the cardiovascular physiology of hibernating bears.

Acknowledgments This work was supported by the National Science Foundation, Minnesota Department of Natural Resources, University of Minnesota Institute for Engineering in Medicine, Colorado Wildlife Management, Wyoming Department of Natural Resources, and Medtronic, Inc.

We thank Pamela L. Coy, Karen V. Noyce, Brian Dirks, Barb Olson, Lixue Yin, Elizabeth Bohn, and Jin Back Hong for technical assistance and Monica Mahre for assistance with manuscript preparation.

\section{References}

1. Austen, M. L., \& Wilson, G. V. (2001). Increased vagal tone during winter in subsyndromal seasonal affective disorder. Biological Psychiatry, 50(1), 28-34.

2. Berntson, C. G., Cacioppo, J. T., \& Quigley, K. S. (1993). Respiratory sinus arrhythmia: Autonomic origins, physiological mechanisms, and psychophysiological implications. Psychophysiology, 30(2), 183-196.

3. Bolling, S. F., Benedict, M. B., Tramontini, N. L., Kilgore, K. S., Harlow, H. H., Su, T. P., et al. (1998). Hibernation triggers and myocardial protection. Circulation, 98 (19 Suppl), II220-II223.

4. Chien, S., Diana, J. N., Oeltgen, P. R., Todd, E. P., O'Connor, W. N., \& Chitwood, W. R., Jr. (1989). Eighteen to 37 hours preservation of major organs using a new autoperfusion multiorgan preparation. Annals of Thoracic Surgery, 47(6), 860-867.

5. Dausmann, K. H., Glos, J., Ganzhorn, J. U., \& Heldmaier, G. (2004). Hibernation in a tropical primate. Nature, 429(6994), $825-826$.

6. Folk, G. E., Jr., Folk, M. A., \& Minor, J. J. (1972). Physiological condition of three species of bears in winter dens. In S. Herrero (Ed.), Bears: Their biology and management (New Series Publication No. 23) (pp. 107-124). Morges: IUCN.

7. Fedorov, V. V., Li, L., Glukhov, A., Shischkina, I., Aliev, R. R., Mikheeva, T., et al. (2005). Hibernator Citellus undulates maintains safe cardiac conduction and is protected against tachyarrhythmias during extreme hypothermia: possible role of Cx43 and Cx45 up-regulation. Heart Rhythm, 2(9), 966-975.

8. Geiser, F., \& Ruf, T. (1995). Hibernation versus daily torpor in mammals and birds: Physiological variables and classification of torpor patterns. Physiological Zoology, 68(6), 935-966.

9. Giles, J. (2004). Could astronauts sleep their way to the stars? News@Nature.com.

10. Harding, J. D., Piacentino, V., III, Gaughan, J. P., Houser, S. R., \& Margulies, K. B. (2001). Electrophysiological alterations after 
mechanical circulatory support in patients with advanced cardiac failure. Circulation, 104(11), 1241-1247.

11. Harlow, H. J., Lohuis, T., Anderson-Sprecher, R. C., \& Beck, T. D. (2004). Body surface temperature of hibernating black bears may be related to periodic muscle activity. Journal of Mammalogy, 85(3), 414-419.

12. Harlow, H. J., Lohuis, T., Beck, T. D. I., \& Iaizzo, P. A. (2001). Muscle strength in overwintering bears. Nature, 409(6823), 997.

13. Harris, M. B., \& Milsom, W. K. (1995). Parasympathetic influence on heart rate in euthermic and hibernating ground squirrels. Journal of Experimental Biology, 198(Pt 4), 931-937.

14. Hellgren, E. C. (1998). Physiology of hibernation in bears. Ursus, $10,467-477$.

15. Hirsch, J. A., \& Bishop, B. (1981). Respiratory sinus arrhythmia in humans: How breathing pattern modulates heart rate. American Journal of Physiology: Heart and Circulatory Physiology, 241(4), H620-H629.

16. Hong, J., Sigg, D. C., Coles, J. A., Jr., Oeltgen, P. R., Harlow, H. J., Soule, C. L., et al. (2005). Hibernation induction trigger reduces hypoxic damage of swine skeletal muscle. Muscle and Nerve, 32(2), 200-207.

17. Khositseth, A., Hejlik, J., Shen, W. K., \& Ackerman, J. M. (2005). Epinephrine-induced T-wave notching in congenital long QT syndrome. Heart Rhythm, 2(2), 141-146.

18. Kondo, N., Sekijima, T., Kondo, J., Takamatsu, N., Tohya, K., \& Ohtsu, T. (2006). Circannual control of hibernation by HP complex in the brain. Cell, 125(1), 161-172.

19. Laske, T. G., Harlow, H. J., Werder, J. C., Marshall, M. T., \& Iaizzo, P. A. (2005). High capacity implantable data recorders: System design and experience in canines and denning black bears. Journal of Biomechanical Engineering, 127(6), 964-971.

20. Levine, B. D., Zuckerman, J. H., \& Pawelczyk, J. A. (1997). Cardiac atrophy after bed-rest deconditioning. Circulation, 96(2), 517-525.

21. Linnell, J. D. C., Swenson, J. E., \& Andersen, R. (2000). How vulnerable are denning bears to disturbance? Wildlife Society Bulletin, 28, 400-413.

22. Lohuis, T., Beck, T. D. I., \& Harlow, H. J. (2005). Hibernating black bears have blood chemistry and plasma amino acid profiles that are indicative of long-term adaptive fasting. Canadian Journal of Zoology, 83(9), 1257-1263.

23. Lohuis, T. D., Harlow, H. J., Beck, T. D. I., \& Iaizzo, P. A. (2007). Hibernating bears conserve muscle strength and maintain fatigue resistance. Physiological and Biochemical Zoology, 80(3), 257269.

24. Milsom, W. K., Zimmer, M. B., \& Harris, M. B. (1999). Regulation of cardiac rhythm in hibernating mammals. Comparative Biochemistry and Physiology, 124(4), 383-391.
25. Moody, G. B., Mark, R. G., Zoccola, A., \& Mantero, S. (1985). Derivation of respiratory signals from multi-lead ECGs. Computers in Cardiology, 12, 113-116.

26. Nelson, O. L., McEwen, M. M., Robbins, C. T., Felicetti, L., \& Christensen, W. F. (2003). Evaluation of cardiac function in active and hibernating grizzly bears. Journal of the American Veterinary Medical Association, 223(8), 1170-1175.

27. Nelson, O. L., Robbins, C. T., Wu, Y., \& Granzier, H. (2008). Titon isoform switching is a major adaptive response in hibernating grizzly bears. American Journal of Physiology. Heart and Circulatory Physiology, 295(1), 366-371.

28. Novotny, T., Sisakova, M., Kadlecova, J., Florianova, A., Semrad, B., Gaillyova, R., et al. (2004). Occurrence of notched T wave in healthy family members with the long QT interval syndrome. American Journal of Cardiology, 94(6), 808-811.

29. Perhonen, M. A., Franco, F., Lane, L. D., Buckey, J. C., Blomqvist, C. G., Zerwekh, J. E., et al. (2001). Cardiac atrophy after bed rest and space flight. Journal of Applied Physiology, 91 (2), 645-653.

30. Perhonen, M. A., Zuckerman, J. H., \& Levine, B. D. (2001). Deterioration of left ventricular chamber performance after bed rest: "cardiovascular deconditioning" or hypovolemia? Circulation, 103(14), 1851-1857.

31. Porges, S. W., \& Byrne, E. (1992). Research methods for measurement of heart rate and respiration. Biological Psychology, 34(2-3), 93-130.

32. Razeghi, P., \& Taegtmeyer, H. (2006). Hypertrophy and atrophy of the heart: The other side of remodeling. Annals of the New York Academy of Sciences, 1080, 110-119.

33. Rogers, L. L., \& Durst, S. C. (1987). Evidence that black bears reduce peripheral blood flow during hibernation. Journal of Mammalogy, 68(4), 876-878.

34. Sigg, D. C., Coles, Jr., J. A., Gallagher, W. J., Oeltgen, P. R., \& Iaizzo, P. A. (2001). Opioid preconditioning: myocardial function and energy metabolism. Annals of Thoracic Surgery, 72, 15761582.

35. Spaak, J., Montmerle, S., Sundblad, P., \& Linnarsson, D. (2005). Long-term bed rest-induced reductions in stroke volume during rest and exercise: Cardiac dysfunction vs. volume depletion. Journal of Applied Physiology, 98(2), 648-654.

36. Summers, R. L., Martin, D. S., Meck, J. V., \& Coleman, T. G. (2005). Mechanism of spaceflight-induced changes in left ventricular mass. American Journal of Cardiology, 95(9), 11281130.

37. Tinker, D. B., Harlow, H. J., \& Beck, T. D. I. (1998). Protein use and muscle-fiber changes in free-ranging, hibernating black bears. Physiological Zoology, 71(4), 414-424. 